\title{
In focus in Prague: intermediate filaments
}

\author{
Jürgen Roth $\cdot$ Paul Debbage $\cdot$ Pavel Hozák
}

Accepted: 25 May 2013/Published online: 7 June 2013

(C) Springer-Verlag Berlin Heidelberg 2013

\begin{abstract}
"Intermediate Filaments in Health and Disease" were the focus of the scientific program of the 55th Symposium of the Society for Histochemistry in Prague, Czech Republic. Various aspects of intermediate filaments (IF) and associated proteins were presented and discussed with emphasis on imaging and sample preparation methods including both light and electron microscopy and specific labeling techniques. The Symposium was organized in cooperation with BMBS COST Action Nanomechanics of Intermediate Filaments Networks (NANONET) and took place in the Conference Center of the Institute of the Molecular Genetics, Academy of Science of the Czech Republic. Pavel Hozák as the local organizer together with his dedicated team did put together a very exciting and representative program.
\end{abstract}

Robert D. Goldman (Northwestern University Medical School, Chicago, USA) presented the "Robert Feulgen Lecture" sponsored by the Society of Histochemistry and communicated "Recent Insights into Cytoskeletal and Nucleoskeletal Intermediate Filaments Networks." Ueli

\footnotetext{
J. Roth $(\bowtie)$

Department of Integrated OMICS for Biomedical Science, WCU Program of Graduate School, Yonsei University, Seoul 120-749, Korea

e-mail: jurgen.roth@yonsei.ac.kr

J. Roth

University of Zurich, 8091 Zurich, Switzerland

P. Debbage

Department of Anatomy, Histology and Embryology, Innsbruck Medical University, 6020 Innsbruck, Austria

P. Hozák

Department of Biology of the Cell Nucleus, Institute of Molecular Genetics of the Academy of Sciences of the Czech Republic, 14220 Prague, Czech Republic
}

Aebi (M.E. Müller Institute for Structural Biology, University of Basel, Switzerland) presented the "EMBO Lecture" and gave a critical appraisal of "IF Research-Quo Vadis?" Nam-On Ku (Yonsei University, Seoul, South Korea) contributed the "Histochemistry and Cell Biology Lecture 2013" and reviewed "Keratin Function in Simple Type Epithelia" (Yi and Ku 2013).

In the Session on "Regulation of IF Assembly and Dynamics in Vivo and in Vitro," Harish C. Pant (Laboratory of Neuronal Cytoskeletal Protein Regulation Section, NINDS, NIH Bethesda, USA) presented an update on the topographic regulation of neuronal IF proteins in health and disease (Binukumar et al. 2013).

In the Session on "IF Structure, Mechanical Properties and Mechanotransduction," Ohad Medalia (Ben-Gurion University, Beer-Sheva, Israel) reviewed structural aspects of lamins and of the nuclear lamina organization as they classically relate to the shape of the nuclear envelope and the nucleus as well as the more recently recognized involvement of lamins in various nuclear functions such as DNA replication and repair, regulation of gene expression, and signaling. A comprehensive and critical appraisal of laminopathies caused by mutations of lamin A, and associated proteins were also presented (Zwerger and Medalia 2013).

In the Session on "IF Associated Proteins and Regulatory Crosstalk in a Cell," Gerhard Wiche (Max F. Perutz Laboratories, University of Vienna, Austria) presented a most comprehensive perspective on plectin-intermediate filament partnership in skin, skeletal muscle, and peripheral nerve. He gave an overview of the structural features and functional properties of plectin and discussed most recent progress in defining the role of its isoforms in stress-prone tissues and the implicated diseases (Castanon et al. 2013). In the same session, Yassemi Capetanaki (Biomedical 
Research Foundation, Academy of Athens, Athens, Greece) focused on the muscle-specific IF desmin and myospryn, a novel desmin-associated TRIM-like protein. The importance of their association for mechanochemical signaling in the regulation of muscle development and homeostasis as well as aspects of the dysregulation of the desmin-myospryn interactome resulting in cardiac and skeletal muscle diseases were assessed (Tsoupri and Capetanaki 2013).

In the Session on "IFs in Pathology and Diagnostics," Nam-On Ku (Yonsei University, Seoul, South Korea) presented the "Histochemistry and Cell Biology Lecture 2013" and reviewed various aspects of keratin function in simple type epithelia ( $\mathrm{Yi}$ and $\mathrm{Ku}$ 2013). Diana Toivola (Åbo Akademi University, Turku, Finland) and her team study keratins in the intestine and endocrine pancreas and their involvement in colitis, colorectal cancer as well as regulation of islet physiology and blood glucose. She reviewed recent findings obtained with keratin-deficient mice.

In the Session "Nuclear Lamins, Chromatin, Nuclear Architecture and Laminopathies," Yosef Gruenbaum (The Hebrew University of Jerusalem, Israel) and Roland Foisner (Medical University Vienna, Austria) reviewed recent advances in the regulation of aging and metabolism by the C. elegans nuclear lamina and the regulation of chromatin organization and gene expression in tissue progenitor cells by nucleoplasmic lamins, respectively.

In the Session on "IFs of the Nervous System: Function in Central Nervous System Pathologies," Joel Eyer (Université d'Angers, France) presented a thorough analysis of the IFs of the nervous system such as neurofilaments, $\alpha$ internexin, glial fibrillary acidic protein, synemin, nestin, peripherin and vimentin and their pathologies as they relate to chronic neurodegenerative disorders and high grade glioma (Lépinoux-Chambaud and Eyer 2013). In the related session on "Neurofilaments: Unexpected Clinical
Findings from Basic Research,” Miloš Pěkný (Sahlgrenska Academy at University of Gothenburg, Sweden) gave an account on the importance of IF for astrocyte response to oxidative stress induced by oxygen-glucose deprivation and reperfusion. In their original work, they demonstrated the importance of IF in the elimination of reactive oxygen species (de Pablo et al. 2013).

Since 1971, the Society for Histochemistry awards the Robert Feulgen Prize. In 2013, the winner of the competition was Yaron Shav-Tal (Bar-Ilan University, Ramat Gan, Israel) for his outstanding contributions to quantify gene expression in single cells by histochemistry (Yunger et al. 2013).

\section{References}

Binukumar BK, Shukla V, Amin ND, Reddy P, Skuntz S, Grant P, Pant HC (2013) Topographic regulation of neuronal IF cytoskeleton phosphorylation, role of peptidyl prolyl isomerase 1 (PIN 1): significance in neurodegeneration. Histochem Cell Biol 140:23-32

Castanon MJ, Walko G, Winter L, Wiche G (2013) Plectinintermediate filament partnership in skin, skeletal muscle, and peripheral nerve. Histochem Cell Biol 140:33-53

De Pablo Y, Nilsson M, Pekna M, Pěkný M (2013) Intermediate filaments are important for astrocyte response to oxidative stress induced by oxygen-glucose deprivation and reperfusion. Histochem Cell Biol 140:77-87

Lépinoux-Chambaud C, Eyer J (2013) Review on intermediate filaments of the nervous system and their pathological alterations. Histochem Cell Biol 140:13-22

Tsoupri E, Capetanaki Y (2013) Myospryn: a multifunctional desmin-associated protein. Histochem Cell Biol 140:55-62

Yi H, Ku N (2013) Intermediates filaments of the lung. Histochem Cell Biol 140:63-67

Yunger S, Kalo A, Kafri P, Sheinberger J, Lavi E, Neufeld N, ShavTal Y (2013) Zooming-in on single active genes in living mammalian cells. Histochem Cell Biol 140:69-76

Zwerger M, Medalia O (2013) From lamins to lamina: a structural perspective. Histochem Cell Biol 140:3-12 